\title{
VERIFICATION OF POTENCY OF AERIAL DIGITAL OBLIQUE CAMERAS FOR AERIAL PHOTOGRAMMETRY IN JAPAN
}

\author{
Ryuji. Nakada $^{\mathrm{a}, *}$, Masanori. Takigawa ${ }^{\mathrm{a}}$, Tomowo. Ohga $^{\mathrm{a}}{ }$ Noritsuna. Fujii $^{\mathrm{a}}$ \\ ${ }^{a}$ Asia Air Survey Co. Ltd., Kawasaki City, Kanagawa Pref, Japan - \\ (ryu.nakada, msa.takigawa, tom.ohga, nor.fujii)@ajiko.co.jp
}

\section{Commission I, WG I/2}

KEY WORDS: Digital Oblique Aerial Camera, Oblique Images, Photogrammetric Accuracy, Bundle Adjustment, Oblique Viewer

\begin{abstract}
:
Digital oblique aerial camera (hereinafter called "oblique cameras") is an assembly of medium format digital cameras capable of shooting digital aerial photographs in five directions i.e. nadir view and oblique views (forward and backward, left and right views) simultaneously and it is used for shooting digital aerial photographs efficiently for generating 3D models in a wide area.

For aerial photogrammetry of public survey in Japan, it is required to use large format cameras, like DMC and UltraCam series, to ensure aerial photogrammetric accuracy.

Although oblique cameras are intended to generate 3D models, digital aerial photographs in 5 directions taken with them should not be limited to 3D model production but they may also be allowed for digital mapping and photomaps of required public survey accuracy in Japan.

In order to verify the potency of using oblique cameras for aerial photogrammetry (simultaneous adjustment, digital mapping and photomaps), (1) a viewer was developed to interpret digital aerial photographs taken with oblique cameras, (2) digital aerial photographs were shot with an oblique camera owned by us, a Penta DigiCAM of IGI mbH, and (3) accuracy of 3D measurements was verified.
\end{abstract}

\section{INTRODUCTION}

\subsection{Background}

The latest development of image processing technology, such as SFM (Structure From Motion) and DIM (Dense Image Matching), has enabled automatic generation of 3D mesh models easily from digital photographs shot consecutively.

In the field of aerial photogrammetry, it is now possible to produce 3D mesh models in vast areas like cities, towns or villages automatically by taking digital aerial photographs with an airborne oblique digital aerial camera assembly (hereinafter called as "oblique cameras") capable of taking vertical and oblique photographs simultaneously.

3D models in vast areas are expected to be used for various purposes including, fixed asset assessment, disaster prevention, sand erosion control, forest conservation, urban scene and flood simulation. However, in Japan, digital aerial photograph shooting with oblique cameras and generation of 3D models are not put in practice for actual surveying as yet. Because for basic surveys and public surveys in Japan, large format digital cameras, like DMC or UltraCam series, are used normally and accuracy standards for 3D models have not been set in Japan. In view of this situation, in order to expand the application of oblique cameras for aerial photogrammetry, a viewer was developed and the accuracy of oblique cameras was verified to prove the potency.

\subsection{Oblique camera assembly}

An oblique camera assembly consists of 5 digital aerial cameras to shoot digital aerial photographs simultaneously in five directions, nadir and oblique (forward, backward, left and right) views. Penta DigiCAM (hereinafter called "PDC") of IGI mbH, Germany, was used for verification of accuracy. Figure 1 shows external view of PDC.

PDC was installed on a Cessna 206 because it can fly relatively at a slow speed to shoot digital aerial photographs of high resolution with high overlapping ratio. Figure 3 shows the concept of photography with PDC.

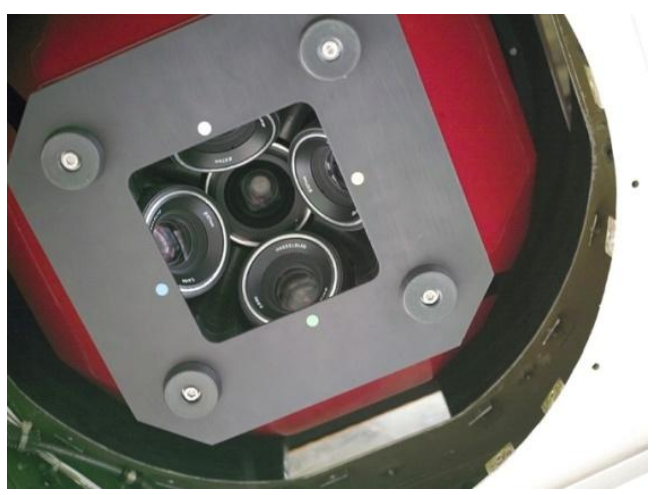

Figure 1. External view of Oblique Camera 


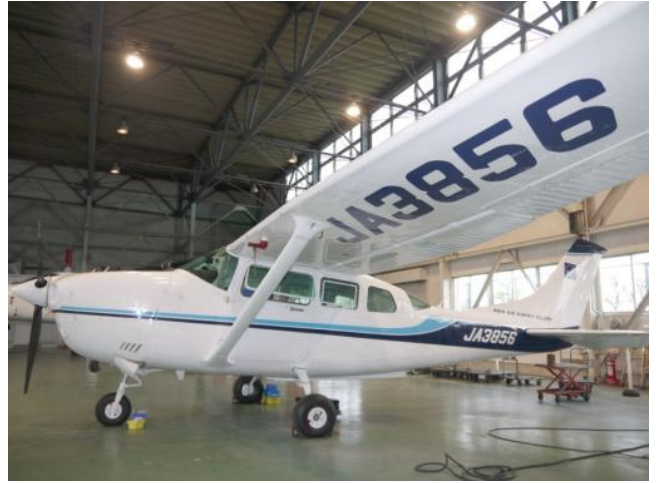

Figure 2. Cessna 206 to install Oblique Camera
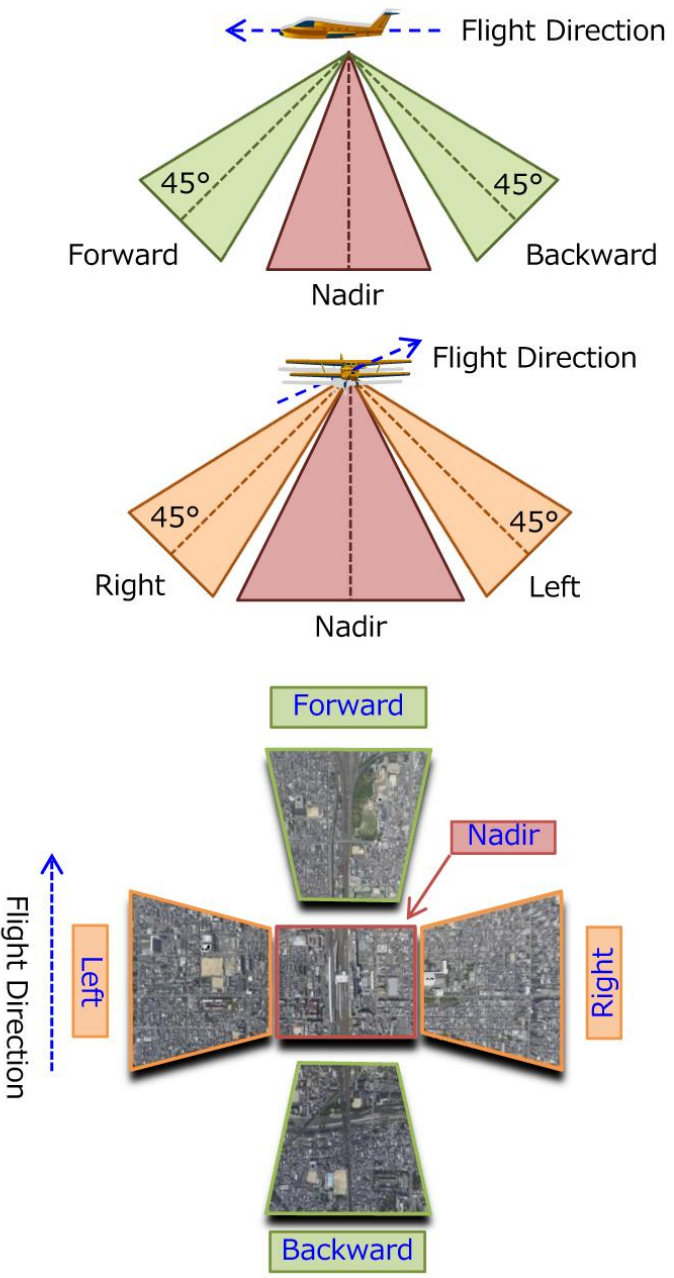

Figure 3. Concept of photography with PDC

\subsection{Composition of PDC system}

PDC is equipped with all devices needed for aerial photogrammetry in Japan and includes GNSS, IMU and Gyro Stabilization Mount. Each camera has 60 million total pixels and oblique view cameras are tilted by 45 degrees. Unlike large format digital aerial cameras, PDC colour data are recorded in Bayer pattern. Table 1 shows the PDC specification.

\begin{tabular}{|c|c|c|}
\hline \multicolumn{2}{|c|}{ Sensor Name } & Penta Digi CAM \\
\hline \multicolumn{2}{|c|}{ Number of Cameras } & $\begin{array}{l}\text { Nadir view: } 1 \\
\text { Oblique view: } 4\end{array}$ \\
\hline \multirow{4}{*}{$\begin{array}{l}\text { Output } \\
\text { image }\end{array}$} & Image Size & $8,956 \times 6,708$ pixels \\
\hline & Total pixels & 60 million $(60,076,848)$ pixels \\
\hline & pixel size & $6.0 \mu \mathrm{m}$ \\
\hline & Focal length & $\begin{array}{l}\text { Nadir view: About } 50 \mathrm{~mm} \\
\text { Oblique view: About } 82 \mathrm{~mm}\end{array}$ \\
\hline \multicolumn{2}{|c|}{ Image resolution } & 16 bit \\
\hline \multicolumn{2}{|c|}{ Base/Height Ratio } & 0.32 \\
\hline
\end{tabular}

Table 1. PDC specification

\section{STUDY ON INTERPRETATION OF PHOTOS}

\subsection{Development of the oblique viewer}

Digital aerial photographs taken in various directions are available because oblique cameras shoot digital aerial photographs in nadir and oblique views simultaneously. These photos provide much more information for management of public facilities and vegetations than on nadir photograph only. It is, however, very difficult to search the digital aerial photographs of an intended object out of large number of digital aerial photographs in 5 directions and this is the reason why utilization of the photos taken with oblique cameras has not been diversified. Therefore a oblique viewer to display digital aerial photographs of oblique cameras was developed to make a breakthrough. Figure 4 shows main screen of the oblique viewer developed by our company. Table 2 shows major functions of the oblique viewer. The biggest advantage of this software is that it can run without installation while public institutions in Japan require approval in advance to install a software.

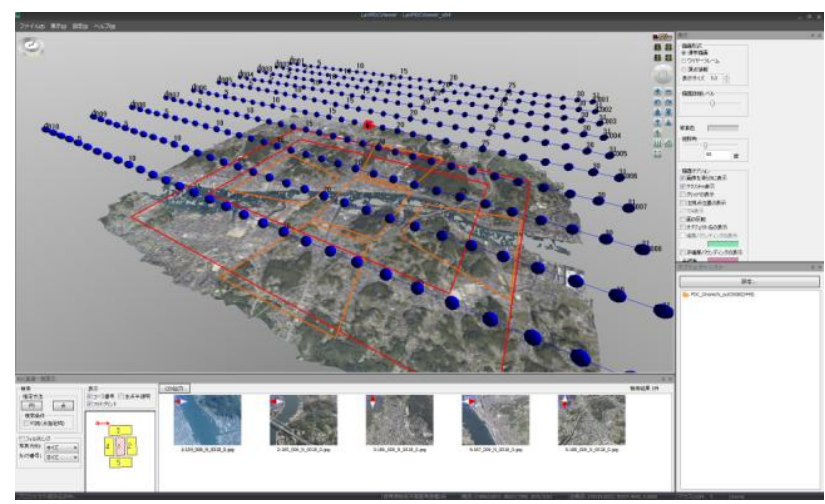

Figure 4. Main screen of the oblique Viewer

\begin{tabular}{|l|l|}
\hline Functions & Feature \\
\hline $\begin{array}{l}\text { Installation is not } \\
\text { needed }\end{array}$ & Direct boot from external HDD \\
\hline Electronic index map & Replaces conventional paper index map \\
\hline Display of footprint & $\begin{array}{l}\text { Displays footprint of photography } \\
\text { principal point }\end{array}$ \\
\hline Photo searching & $\begin{array}{l}\text { Retrieves aerial photos of any desired } \\
\text { point }\end{array}$ \\
\hline Print & Prints out images retrieved \\
\hline
\end{tabular}

Table 2. Major functions of the oblique viewer 


\subsection{Effect of the oblique viewer when interpreting digital aerial photographs}

When interpreting digital aerial photographs, most operators search intended digital aerial photographs manually by collating the point to investigate with an index map of the area. For example, the bridge column of Figure 5 is consists of 71 photos in nadir and oblique view images and it is extremely time consuming to search manually the photos needed for interpreting digital aerial photographs.

This newly developed oblique viewer enables to search automatically the digital aerial photographs of the point of investigation and greatly reduces the time for searching. In addition, the oblique viewer can display multiple digital aerial photographs at a time to confirm the point of investigation from various angles and improves accuracy of digital aerial photographs interpretation. It will, consequently, stimulate application of digital aerial photographs taken with oblique cameras.

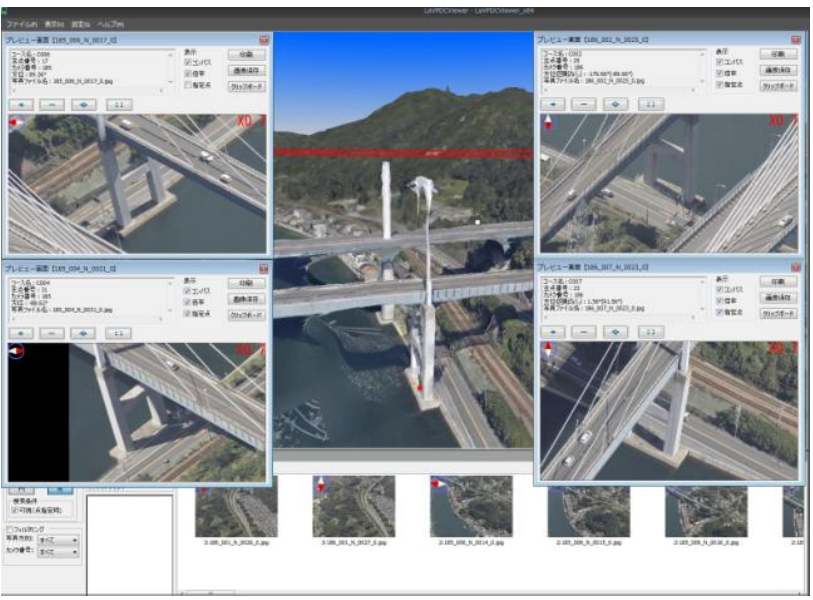

Figure 5. digital aerial photographs of a bridge column

\section{TEST FIELD FOR ACCURACY VERIFICATION}

\subsection{Test field}

The digital aerial photographs were taken in a test field with forward overlap ratio of $60 \%$ and side overlap ratio of $30 \%$ on nadir view image. GSD(Ground sampling distance) was set at $7.6 \mathrm{~cm}$ which complies with the map information level of 500 (5.8 7.7 cm according to Criterion No. 124-4 of Public Survey Working Rules). 5 control points and 13 check points used for verifying the accuracy were observed both on plane and in altitude with standard deviation of $0.02 \mathrm{~m}$. Table 3 shows photography conditions and Figure 6 shows the test field.

\begin{tabular}{|c|c|}
\hline $\begin{array}{c}\text { Map information } \\
\text { level }\end{array}$ & Calculating formula of GSD \\
\hline 500 & $90 \mathrm{~mm} \times 2 \times \mathrm{B}[\mathrm{m}] \div \mathrm{H}[\mathrm{m}] \sim 120 \mathrm{~mm} \times 2 \times \mathrm{B}[\mathrm{m}] \div \mathrm{H}[\mathrm{m}]$ \\
\hline 1000 & $180 \mathrm{~mm} \times 2 \times \mathrm{B}[\mathrm{m}] \div \mathrm{H}[\mathrm{m}] \sim 240 \mathrm{~mm} \times 2 \times \mathrm{B}[\mathrm{m}] \div \mathrm{H}[\mathrm{m}]$ \\
\hline 2500 & $300 \mathrm{~mm} \times 2 \times \mathrm{B}[\mathrm{m}] \div \mathrm{H}[\mathrm{m}] \sim 375 \mathrm{~mm} \times 2 \times \mathrm{B}[\mathrm{m}] \div \mathrm{H}[\mathrm{m}]$ \\
\hline & " $\mathrm{B}$ " is Base length and " $\mathrm{H}$ " is Altitude above ground in the list.
\end{tabular}

Figure 5. Map information level and corresponding GSD

\begin{tabular}{|l|l|}
\hline Location of Test Field & Itabashi, Tokyo \\
\hline Focal length & $50 \mathrm{~mm} / 82 \mathrm{~mm}$ \\
\hline Date of shooting & Oct. 25, 2014 \\
\hline Altitude above ground & $637 \mathrm{~m} / 902 \mathrm{~m}$ \\
\hline Ground sampling distance & $7.6 \mathrm{~cm} / 6.6 \mathrm{~cm}$ \\
\hline Forward overlap ratio & $60 \% / 57 \%-74 \%$ \\
\hline Side overlap ratio & $30 \% / 0 \%-39 \%$ \\
\hline Number of shooting points & 203 points \\
\hline Number of courses & 7 \\
\hline
\end{tabular}

Meaning of the " / " mark of the list is Nadir view/Oblique view.

Table 3. PDC photography conditions

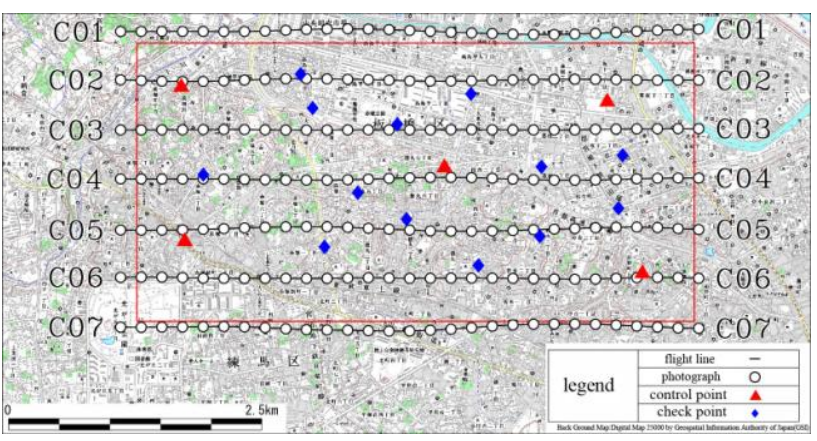

Figure 6. Test field

\section{ACCURACY VERIFICATION METHOD}

\subsection{Legibility of PDC digital images}

An area was selected within the test field and legibility was verified by comparing the nadir and oblique views of PDC with the digital images shot with a DMC camera with the same GSD as PDC.

\subsection{Accuracy verification by simultaneous adjustment calculation}

Simultaneous adjustment calculation of the digital images taken with PDC was made on each of the following 6 block configurations, i.e. 1) Nadir view image only, 2) Forward view image only, 3) Left view image only, 4) Oblique view images (forward, backward, left and right) only, 5) 5 view images (integrate oblique views after orienting nadir view) and 6) 5 view images (orienting 5 views simultaneously).Figure 7 shows the block configurations.

The purpose of the verification in each block:

In the block composition of 1), 2), 3), accuracy of simultaneous measurement of nadir view image and oblique view images are individually checked.

In the block composition of 4), 5), 6), accuracy of simultaneous measurement of 4-directions (shot by multiple oblique view images) is checked and 5-directions (shot by 1 nadir view image and 4 oblique view images) is also checked.

Bing-AT was used for simultaneous adjustment calculation. Tie points were acquired by automatic image matching by means of Match-AT. The results of accuracy verification was evaluated by comparing intersection residuals and control point residuals 
with the values specified as the criteria of map information level of 500 of Public Survey Working Rules.
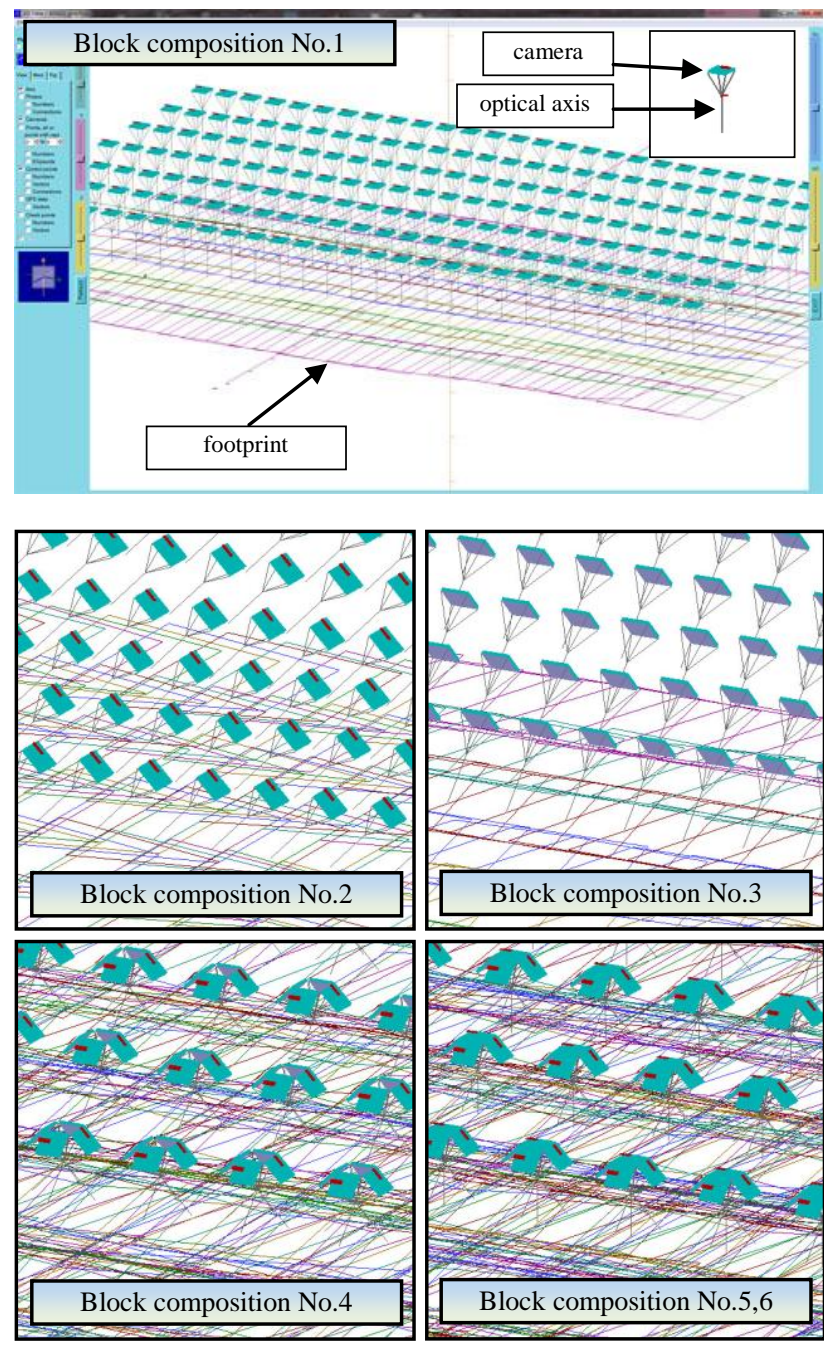

Figure 7. Block composition when calculating simultaneous adjustment

\subsection{Accuracy verification of stereo measurement}

Check point position was stereo measured by means of exterior orientation of each block configuration calculated by simultaneous adjustment and then check point residuals were verified.

\subsection{Comparison of nadir view image with oblique view images for digital mapping}

It was expected the measurement accuracy would vary within the same stereo pair of oblique view images because GSD was different between near and far sides due to difference of distance from the camera station. 35 points (like white lines painted on the road in the same area) identical both in nadir and oblique view images were mapped to check the difference. Mapping was also made for an area only by oblique view images to study the possibility of using oblique view images for mapping and the results were compared with the mapping by nadir view images only. Exterior orientation of block configuration 5) and nadir and left view images were used for mapping.

\section{THE RESULT OF THE ACCURACY VERIFICATION}

\subsection{Legibility of PDC digital images}

The features on nadir and oblique view images of PDC were compared with the image shot with a DMC camera for the same place. The result showed that all features on DMC camera images were legible in nadir and oblique view images of PDC. Figure. 8 shows the Comparison of images of PDC and DMC.

As for PDC image quality, colour blurring and false colour had been worried about due to Bayer pattern but nothing was found to disturb image interpretation or mapping. Figure.9 shows the enlarged PDC image. Consequently it was concluded that both nadir and oblique view images of PDC can be used for interpretation of the digital aerial photographs. Improvement of legibility of wall information (walls and posts) is expected by using oblique view images.

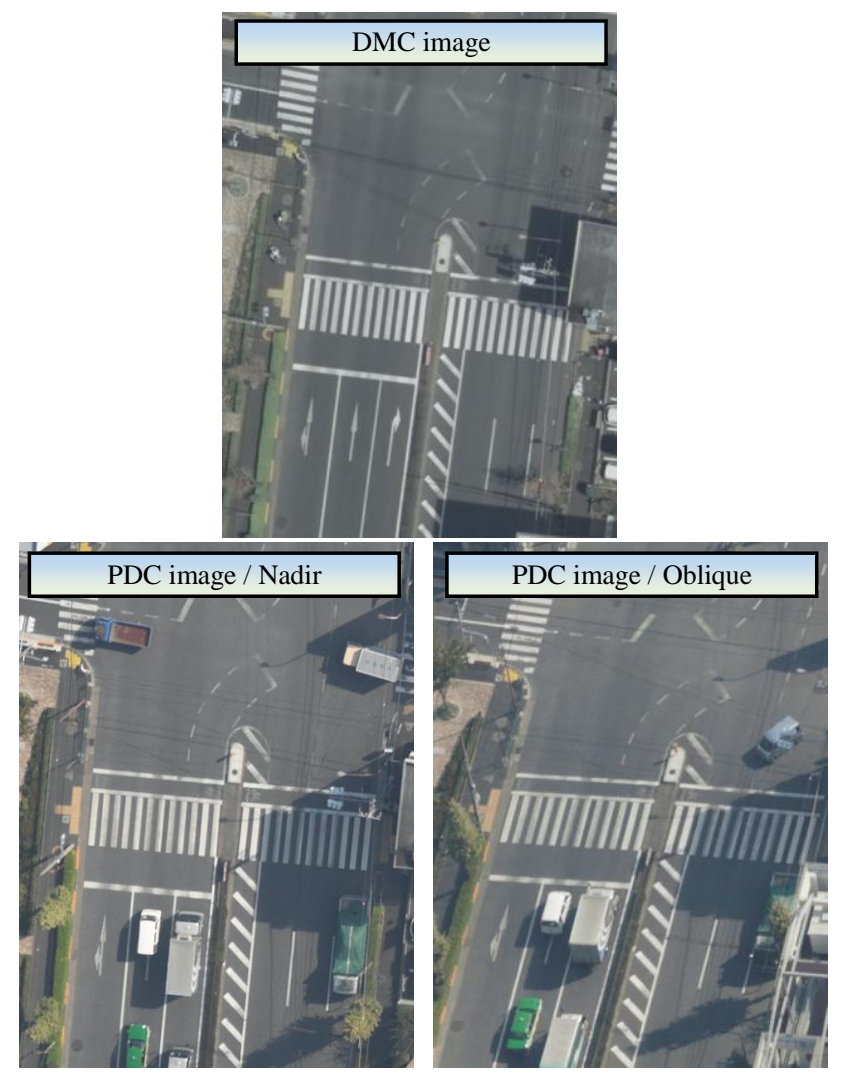

Figure 8. Comparison of images of PDC and DMC
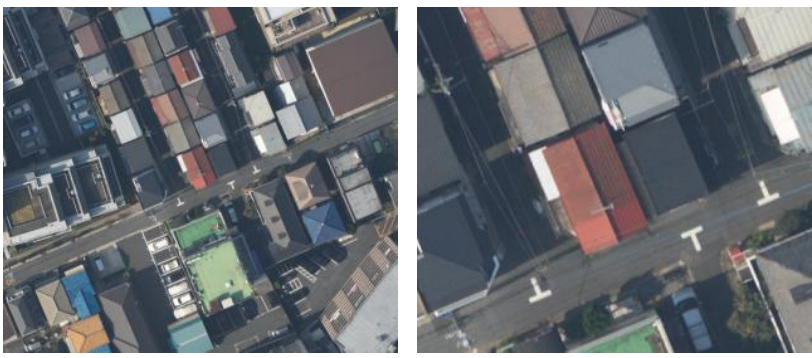

Figure 9. Enlarged PDC image 


\subsection{Result of accuracy verification by simultaneous adjustment calculation}

Figure 10 and 11 show image coordinates residuals and control point residuals of each block configuration. These residuals satisfied the criteria of Public Survey Working Rules (Image coordinates residuals: Root Mean Squared Error[RMSE] 4.5 $\mu \mathrm{m}$, Max. $9.0 \mu \mathrm{m}$, Control point residuals: Max. $0.24 \mathrm{~m}$ ). Particularly the block configurations of 1), 5) and 6) showed good results of simultaneous adjustment calculation, which means the nadir view image played an important role to improve accuracy of the calculation.

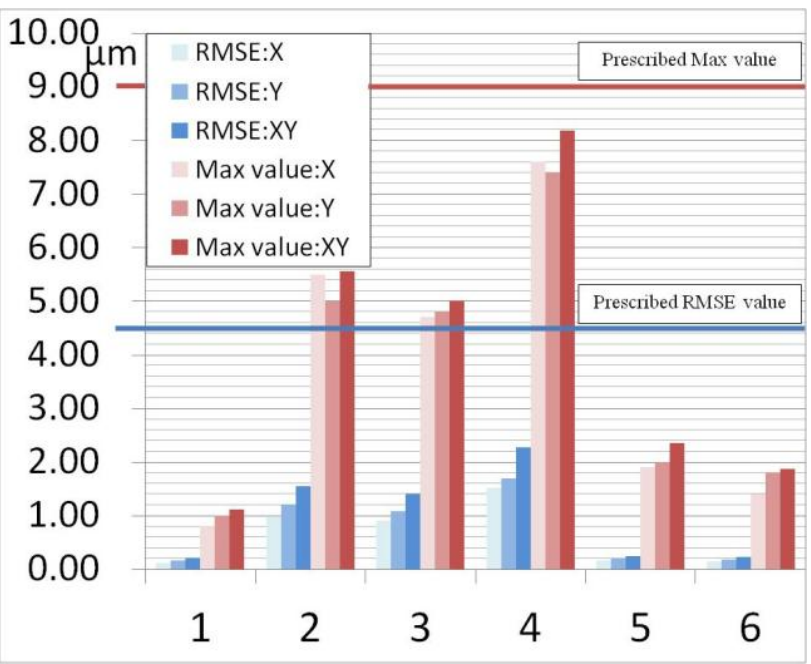

Figure 10. image coordinates residuals of each block

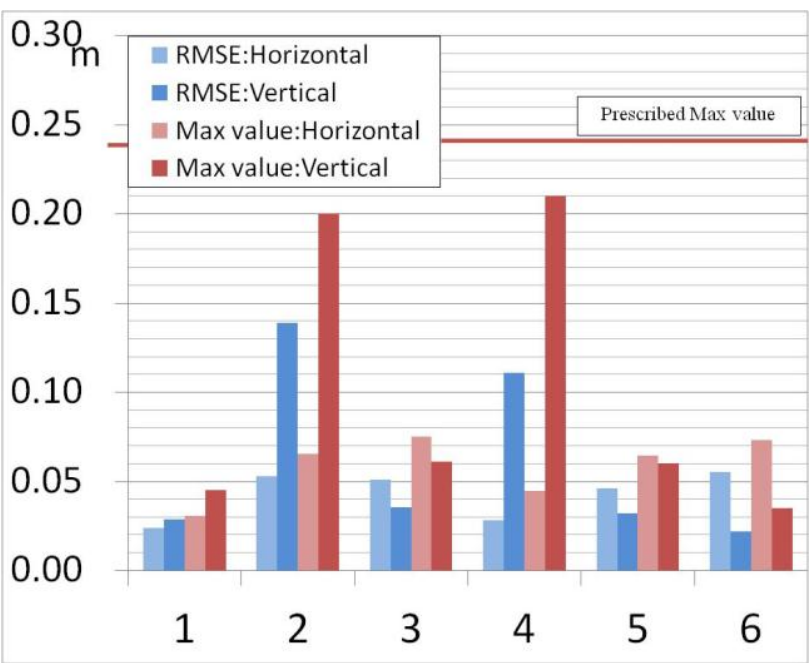

Figure 11. Control point residuals of each block

\subsection{Result of accuracy verification of stereo measurement}

Figure 12 and 13 show standard deviations and maximum values of check point residuals obtained by stereo measurement in all block configurations.

Result of the verification:

RMSE in all block configurations were found within the criterion of the Public Survey Rules (RMSE of $0.25 \mathrm{~m}$ for both horizontal and vertical positions). Measurement accuracy in nadir view image was found almost equal in any block configurations (1), 5), and 6) ), but some variation was found in oblique view images. Probable causes of the variation are different GSDs on near and far sides of oblique view image and proficiency of the operator in oblique view image.

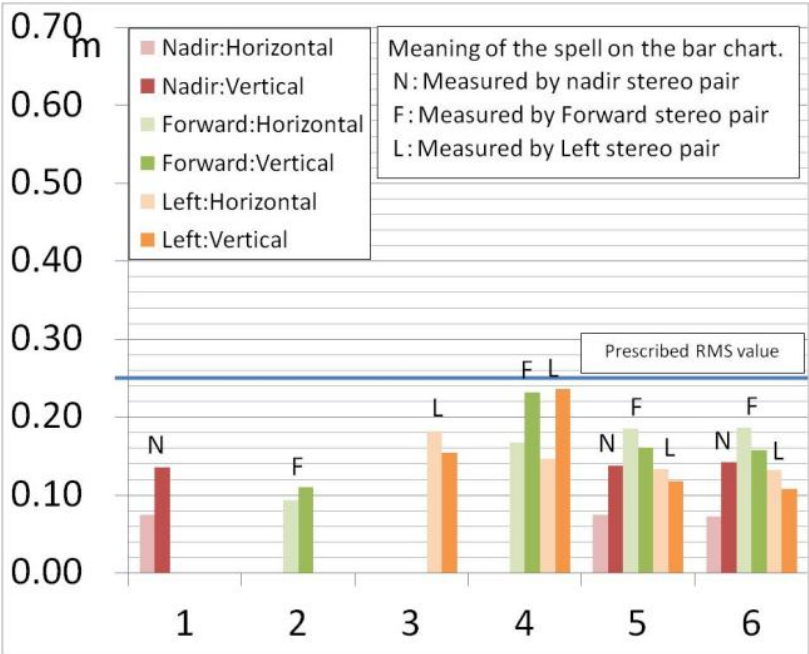

Figure 12. RMS of stereo measurement in each block configuration

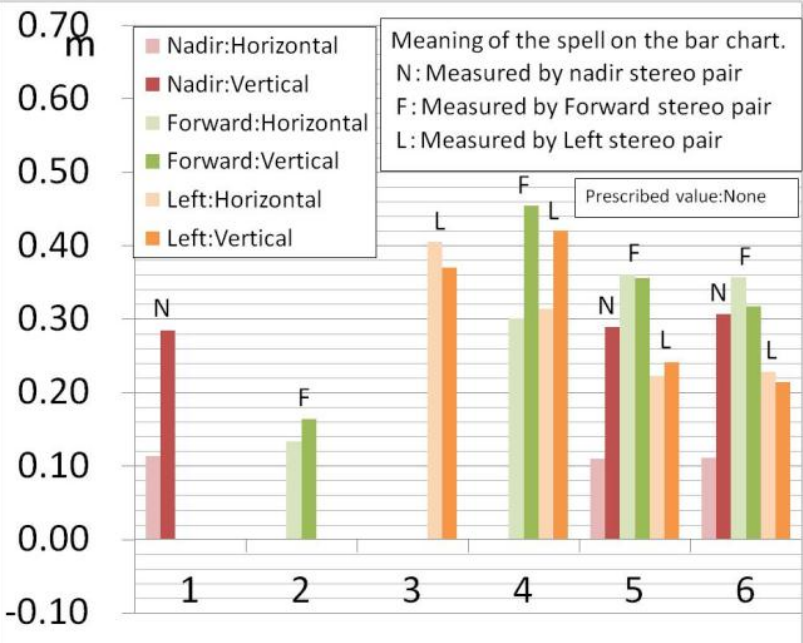

Figure 13. Maximum residual of stereo measurement in each block configuration

\subsection{Result of comparison of nadir view image and oblique view images digital mapping}

Figure 14 and Table 4 show the comparison of mapping the identical points in nadir view image and oblique views images. The verification showed no large difference of RMSE both in horizontal and vertical positions. Figure 15 shows the results of mapping of an area only by nadir view image and only by oblique view images. When they are superimposed a difference of about $50 \mathrm{~cm}$ in horizontal distance was found but no other significant difference was found. Consequently oblique view images are expected to be used for digital mapping in aerial photogrammetry. 
However, the maximum difference was found at the farthest end in oblique view image as shown in Figure 14 and Table 4, and consequently it is necessary to study further an appropriate range of distance from the camera station to be used in oblique view images.

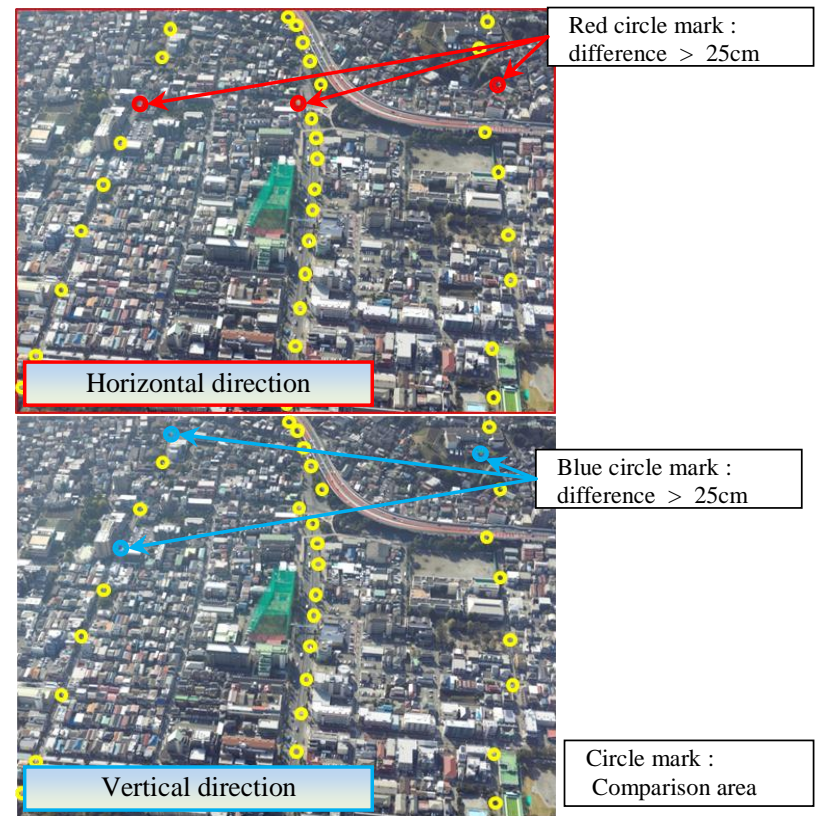

Figure 14. Area of comparison

\begin{tabular}{|c|c|c|}
\hline & Horizontal & Vertical \\
\hline RMSE & $0.13 \mathrm{~m}$ & $0.11 \mathrm{~m}$ \\
\hline Maximum & $0.44 \mathrm{~m}$ & $0.28 \mathrm{~m}$ \\
\hline
\end{tabular}

Table 4. Comparison of digital mapping, Nadir view image and Oblique view images
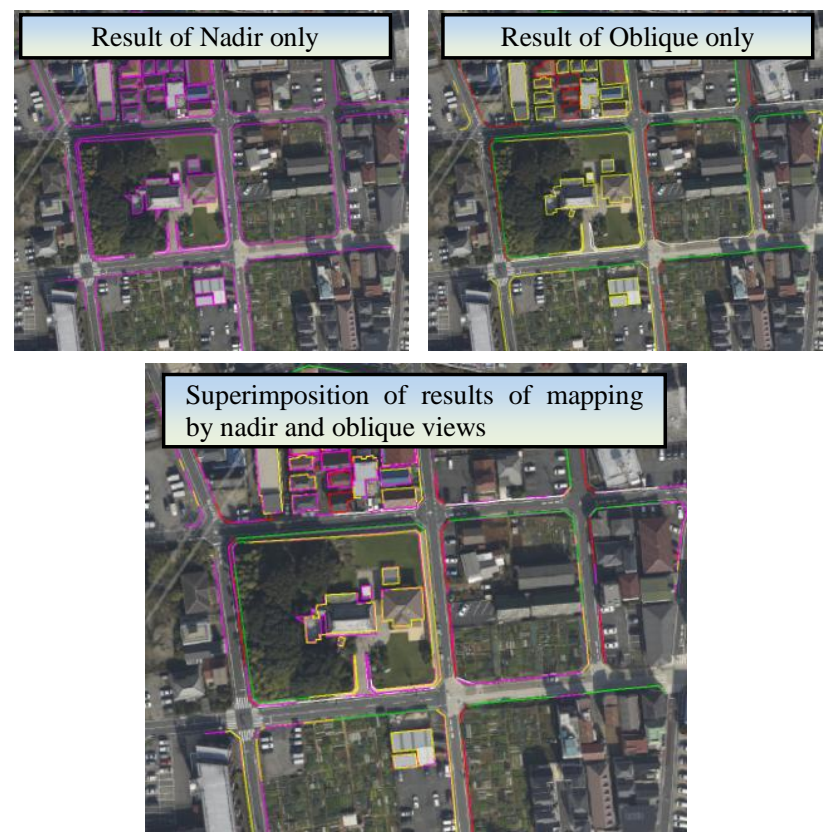

Figure. 15 Result of accuracy verification Superimposition of results of mapping by nadir and oblique view images

\section{CONCLUSION}

It was confirmed that the newly developed viewer can handle large number of digital aerial photographs taken with oblique cameras and improve accuracy of interpretation.

It was also confirmed that simultaneous adjustment calculation and stereo measurement using nadir and oblique view images of oblique cameras satisfy the current criteria of aerial photogrammetry in Japan.

As a result it is expected that oblique cameras will be used more widely in the field of aerial photogrammetry including photo shooting, digital mapping and photomap.

Compared with nadir view image, some variation was found in measuring accuracy in oblique view images. Therefore it will be necessary to continue the study on how to apply oblique view images to digital mapping.

\section{REFERENCES}

Dieter FRITSCH, Mathias ROTHERMEL : Oblique Image Data Processing - Potential, Experiences and Recommendations, Photogrammetric Week'13, pp. 73-88

Remondino F, Gerke M, : Oblique Aerial Imagery - A Review, Photogrammetric Week'15, pp. 75-83

Madani, M. , 2012. ACUURACY POTENTIAL AND APPLICATIONS OF MIDAS AERIAL OBLIQUE CAMERA SYSTEM, In: The International Archives of the Photogrammetry, Remote Sensing and Spatial Information Sciences, Melbourne, Australia, Vol. XXII, pp. 127-132

Ryuji N., 2015. JSPRS Fall Conference in 2015, Hokkaido, Japan, pp. 145-146

Guidance of Public Survey by Geospatial Information Authority of Japan. 